\title{
Elucidating the biological basis for the reinforcing actions of alcohol in the mesolimbic dopamine system: the role of active metabolites of alcohol
}

\author{
Gerald A. Deehan Jr*, Sheketha R. Hauser, Jessica A. Wilden, William A. Truitt and Zachary A. Rodd
}

Department of Psychiatry, Institute of Psychiatric Research, Indiana University, School of Medicine, Indianapolis, IN, USA

\section{Edited by:}

Elio Acquas, University of Cagliari, Italy

\section{Reviewed by:}

Miriam Melis, University of Cagliari, Italy

Roberto Ciccocioppo, University of Camerino, Italy

Yedy Israel, University of Chile, Chile

\section{*Correspondence:}

Gerald A. Deehan Jr, Department of Psychiatry, Institute of Psychiatric Research, Indiana University, School of Medicine, 791 Union Drive, Indianapolis, IN 46202-4887, USA e-mail:gdeehan@iupui.edu
The development of successful pharmacotherapeutics for the treatment of alcoholism is predicated upon understanding the biological action of alcohol. A limitation of the alcohol research field has been examining the effects of alcohol only and ignoring the multiple biological active metabolites of alcohol. The concept that alcohol is a "pro-drug" is not new. Alcohol is readily metabolized to acetaldehyde within the brain. Acetaldehyde is a highly reactive compound that forms a number of condensation products, including salsolinol and iso-salsolinol (acetaldehyde and dopamine). Recent experiments have established that numerous metabolites of alcohol have direct CNS action, and could, in part or whole, mediate the reinforcing actions of alcohol within the mesolimbic dopamine system. The mesolimbic dopamine system originates in the ventral tegmental area (VTA) and projects to forebrain regions that include the nucleus accumbens (Acb) and the medial prefrontal cortex (mPFC) and is thought to be the neurocircuitry governing the rewarding properties of drugs of abuse. Within this neurocircuitry there is convincing evidence that; (1) biologically active metabolites of alcohol can directly or indirectly increase the activity of VTA dopamine neurons, (2) alcohol and alcohol metabolites are reinforcing within the mesolimbic dopamine system, (3) inhibiting the alcohol metabolic pathway inhibits the biological consequences of alcohol exposure, (4) alcohol consumption can be reduced by inhibiting/attenuating the alcohol metabolic pathway in the mesolimbic dopamine system, (5) alcohol metabolites can alter neurochemical levels within the mesolimbic dopamine system, and (6) alcohol interacts with alcohol metabolites to enhance the actions of both compounds. The data indicate that there is a positive relationship between alcohol and alcohol metabolites in regulating the biological consequences of consuming alcohol and the potential of alcohol use escalating to alcoholism.

Keywords: acetaldehyde, salsolinol, ethanol, reinforcement (psychology), reward, dopamine

\section{INTRODUCTION}

Alcoholism and alcohol (EtOH) abuse is a global burden. Alcoholism is estimated to be responsible for $3.8 \%$ of all global deaths, and cost associated with treatment equivalent to $1 \%$ of gross national product of high- and medium-income countries (Rehm et al., 2009). As such, a great deal of research has focused on therapeutic interventions to aid individuals that are currently suffering from alcoholism and a great deal of effort has been put forth to identify neurobiological traits that are common in individuals that are at a high-risk to develop an alcohol-use disorder. However, while several lines of research have emerged

\footnotetext{
Abbreviations: Triazole, 3-amino-1,2,4-triazole; ACD, Acetaldehyde; $\mathrm{ADH}$, Alcohol Dehydrogenase; ALDH, Aldehyde Dehydrogenase; CNS, Central Nervous System; CPP, Conditioned Place Preference; $\mathrm{D}_{2}$, Dopamine 2; DA, Dopamine; EtOH, Ethanol; GABA, Gamma-aminobutyric Acid; GLU, Glutamate; ICV, Intra-Cerebral Ventricular; IV, Intra-venous; $\mu \mathrm{M}$, Micro-molar; mM, Milli-molar; MOR, Mu Opioid Receptor; AcbC, Nucleus Accumbens Core; AcbSh, Nucleus Accumbens Shell; Acb, Nucleus Accumbens; $5 \mathrm{HT}_{3}$, Serotonin 3; 5-HT, Serotonin; TBCs, Tetrahydrobetacarbolines; SAL, Salsolinol; THIQs, Tetrahydroisoquinoline alkaloids; THP, Tetrahydropapaveraoline; FDA, United States Food and Drug Administration; VTA, Ventral Tegmental Area.
}

focusing on the many different facets of EtOH addiction the biological basis of the reinforcing properties of $\mathrm{EtOH}$ has not been completely established. Opposing theories have emerged with some suggesting that it is the action of the $\mathrm{EtOH}$ molecule itself that underlies the rewarding properties of EtOH. Others believe that EtOH is simply a "pro-drug" and the rewarding properties of EtOH are dependent on the action of the metabolites/byproducts of $\mathrm{EtOH}$ within the brain. The main principles underlying the "pro-drug" theory assert that (1) following EtOH consumption, EtOH concentrations within the body are unable to reach levels that adequately affect the central nervous system (CNS), (2) various behavioral and physiological effects of $\mathrm{EtOH}$ endure well past the bioavailability of EtOH in the system, and (3) manipulation of the metabolism of $\mathrm{EtOH}$, and the subsequent formation of the metabolites and/or byproducts, within the system affects most, if not all, of the CNS effects of EtOH. The contrary theory suggests that EtOH affects several neurotransmitter systems thereby exerting its effects within the CNS. Proponents of this theory suggest there is no conclusive evidence that the metabolites of $\mathrm{EtOH}$ possess the ability to 
cross the blood brain barrier and the metabolites exists for too short a period to mediate the more persistent effects of EtOH intoxication. Regardless of such polarized stances, EtOH reward within the CNS likely depends on the action of EtOH in conjunction with its metabolites/byproducts. This review will present an overview of the behavioral and neurochemical actions of the neuroactive metabolite acetaldehyde (ACD), and subsequent metabolites/byproducts (i.e., salsolinol) formed through the reaction/condensation of ACD with endogenous compounds, within the central and peripheral nervous systems following $\mathrm{EtOH}$ intake.

\section{THE FIRST METABOLITE OF ALCOHOL: ACETALDEHYDE}

It has been well established that high levels of ACD within the periphery are associated with aversive symptoms (i.e., flushing, headaches, etc.). The drug disulfuram (tetraethylthiuramdisulphide), which has been approved for the treatment of alcoholism, exacerbates the aversive symptoms of ACD by inhibiting the metabolism of ACD thereby encouraging individuals to abstain from EtOH consumption. The mechanisms of action behind disulfuram treatment were discovered serendipitously. In the early 20th century, a report emerged describing individuals who worked in a metal manufacturing plant experiencing transitory aversive symptoms (i.e., fatigue, shortness of breath, flushing of the face, increased heart rate, headaches) following the consumption of alcoholic beverages (Koelsch, 1914). Such symptoms were subsequently linked to the compound calcium cyanamide, an organic compound used in the production of metals, which the workers were in regular contact with. Similar symptoms were reported shortly thereafter in patients that had consumed ink cap mushrooms prior to drinking $\mathrm{EtOH}$; a reaction that was linked to the amino acid coprine present in the mushroom (Chifflot, 1916; Reynolds and Lowe, 1965). Two decades later, Williams (1937) suggested that the cure of alcoholism may have been discovered as workers at a rubber plant that were exposed to the compound tetramethylthiuram experienced similar aversive symptoms to those outlined above when they consumed EtOH.

Soon thereafter, two researchers, Erik Jacobsen and Jens Hald, began examining tetraethylthiuramdisulphide (disulfuram) as a possible treatment for intestinal worms. Utilizing themselves as test subjects, both men reported experiencing several aversive symptoms following $\mathrm{EtOH}$ consumption (i.e., sleepiness, increased heart rate, etc.; Jacobsen, 1958). Follow-up studies indicated that disulfuram, since marketed as antabuse, acted to block aldehyde dehydrogenase, an enzyme that metabolizes ACD, causing increased blood ACD levels thereby increasing the aversive side effects of EtOH consumption (Hald and Jacobsen, 1948). Early studies had already indicated a positive correlation between $\mathrm{EtOH}$ intake and increased blood ACD levels such that binge drinkers exhibited ACD levels 35 times greater than controls (Stotz, 1943). However, additional studies indicated that social drinkers treated with antabuse exhibited blood ACD levels 5-10 times greater than individuals that did not receive the treatment (Hald and Jacobsen, 1948; Larsen, 1948). Treating individuals with antabuse, prior to $\mathrm{EtOH}$ consumption, allowed for the detection of ACD in the breath (Hald and Jacobsen, 1948). Preclinical research indicated that antabuse rendered ACD detectable in the breath of rabbits following $\mathrm{EtOH}$ exposure and research aimed at the identification of the metabolic pathway of EtOH began (Hald et al., 1949a,b).

Over the next 30 years, several theories emerged as to the function of ACD in EtOH-use disorders (Carpenter and Macleod, 1952; Myers and Veale, 1969; Davis and Walsh, 1970; Truitt and Walsh, 1971; Griffiths et al., 1974). A number of theories identified EtOH as a "pro-drug" suggesting alcoholism would be better termed "acetaldhydeism" as ACD was responsible for all of the effects associated with the imbuement of EtOH (Truitt and Walsh, 1971; Raskin, 1975). Contradictory theories asserted that ACD in no way mediated the effects of EtOH. Such assertions were supported by research showing that the consumption of EtOH produced only trace levels of ACD in the cerebrospinal fluid and brain (Kiianmaa and Virtanen, 1978; Pikkarainen et al., 1979; Eriksson et al., 1980) and that ACD was unable to cross the blood brain barrier except when in exceedingly high concentrations (Sippel, 1974; Tabakoff et al., 1976; Eriksson, 1977; Petersen and Tabakoff, 1979). However, Cohen et al. (1980) reported that the local formation of ACD within the brain was possible thereby reestablishing the $\mathrm{ACD} / \mathrm{EtOH}$ debate.

\section{ACETALDEHYDE AND ALCOHOLISM: A GENETIC PERSPECTIVE}

Following consumption, EtOH undergoes a number of reactions as it is metabolized. The primary pathway through which EtOH is eliminated from the body involves the action of the alcohol dehydrogenase $(\mathrm{ADH})$ and aldehyde dehydrogenase (ALDH) enzymes (for review see: Deehan et al., 2013). The action of $\mathrm{ADH}$ oxidizes $\mathrm{EtOH}$ which results in the formation of ACD which is subsequently eliminated/metabolized by ALDH into acetate and eliminated from the body (for schematic depiction of EtOH metabolism see Figure 1). Alterations in either class of enzyme have been shown to produce alterations in ACD levels. An increase in the formation of ACD has been found to lead to an increase in the aversive symptoms (i.e., flushing, nausea, etc.) associated with $\mathrm{EtOH}$ consumption thereby decreasing further motivation to consume EtOH (Peng and Yin, 2009). Genetic studies have identified genetic polymorphisms in both $\mathrm{ADH}$ and ALDH which have been linked to a decreased susceptibility to develop an EtOH-use disorder (Edenberg, 2011). For instance, a recent study reported that Mexican Americans expressing the $\mathrm{ADH}_{13}{ }^{2} 2$ genotype were protected against EtOH-dependence (Ehlers et al., 2012). Such protection, against EtOH-dependence, likely occurs through a more rapid oxidation of EtOH resulting in significantly higher levels of peripheral ACD (Hurley and Edenberg, 2012). Research has indicated that an alteration in the expression of the ALDH2 gene results in a slower oxidation of ACD to acetate thereby resulting in a "Disulfiram-like" experience due to greater ACD levels (Ball, 2008). Recent endeavors have identified a polygenic contribution of the ADH gene cluster suggesting a potential role for several of the $\mathrm{ADH}$ genes in the development of alcoholism (Frank et al., 2012).

\section{ACETALDEHYDE FORMATION WITHIN THE CNS}

Following the intake of EtOH, ACD is formed in the periphery, primarily by the activity of $\mathrm{ADH}$ in the liver. However, given high activity of aldehyde dehydrogenase (ALDH; the primary enzyme responsible for metabolizing $\mathrm{ACD}$ ) within the blood brain barrier 


\section{Central (Brain) Metabolism}

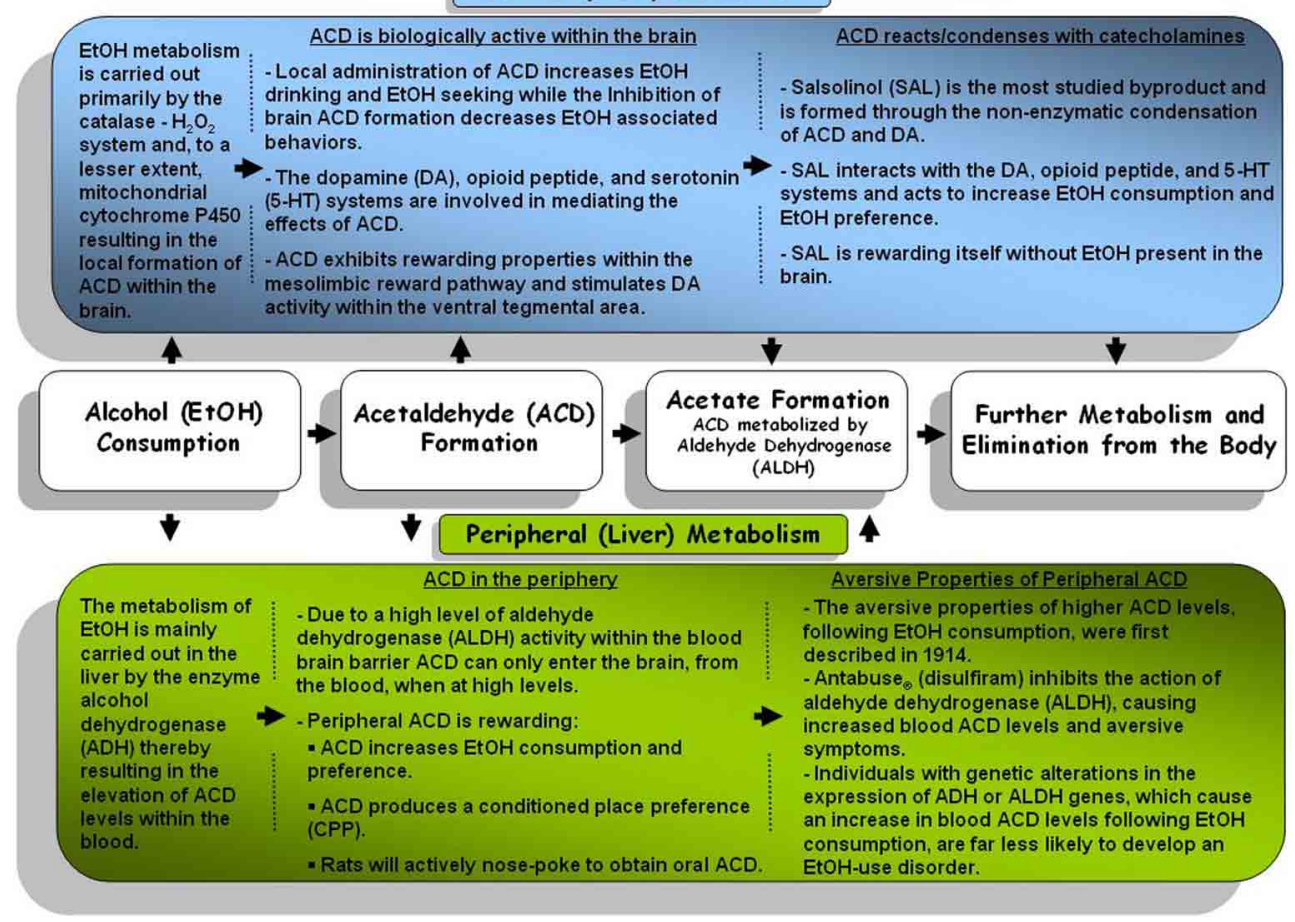

FIGURE 1 | A general schematic representation of the central (brain) and peripheral (body) metabolism pathways for alcohol and alcohol metabolites.

it was widely accepted that very little ACD could commute into the brain from the periphery (Hunt, 1996). Additional studies indicated that higher levels of ACD within the periphery may be capable of overwhelming peripheral ALDH, entering the brain within minutes (Ward et al., 1997; Quertemont et al., 2005). Metabolic activity resulting in the local formation of ACD within brain was not immediately clear and has been the topic of debate for several years. Research has indicated that $\mathrm{ADH}$ is not active within the brain and has established that $\mathrm{EtOH}$ is primarily metabolized through the activity of the catalase enzyme (Sippel, 1974; Zimatkin, 1991; Smith et al., 1997) and this enzyme remains relatively constant across different rat strains (Rhoads et al., 2012). In vivo studies support the activity of catalase as a key component in the formation of brain ACD following $\mathrm{EtOH}$ exposure as inhibition of catalase activity subsequently decreased brain ACD levels (Jamal et al., 2007). However, inhibition of catalase does not completely abolish ACD formation. Other metabolic pathways such as mitochondrial cytochrome $\mathrm{P} 450$ have also been found to produce ACD locally within the brain following the consumption of EtOH (Zimatkin et al., 1998; Zakhari, 2006). In mice, manipulation of cytochrome $\mathrm{P} 450$ has been found to alter overall sensitivity to EtOH (Vasiliou et al., 2006), EtOH consumption, and $\mathrm{EtOH}$ stimulated locomotor activity (Correa et al., 2009).

\section{IMPLICATION OF ACD IN THE CENTRAL ACTIONS OF EtOH}

Several studies that have made use of compounds that act to inhibit the formation of ACD or sequester ACD into a stable non-reactive adduct. Such experiments have implicated the local formation of ACD as an important aspect of the neurobiological and behavioral aspects of EtOH use/abuse. The compounds sodium azide and/or 3-amino-1,2,4-triazole (triazole) inhibit catalase activity, thereby decreasing ACD formation within the brain, and have been shown to alter $\mathrm{EtOH}$ related behaviors. For instance, both sodium azide and triazole significantly altered $\mathrm{EtOH}$-induced locomotor activity when infused into the arcuate nucleus of the hypothalamus (Sanchis-Segura et al., 2005; Pastor and Aragon, 2008). Triazole has also been found to decrease the consumption of EtOH in both rats and mice (Aragon and Amit, 1992; Koechling and Amit, 1994), reduce EtOH induced motor depression in rats (Aragon et al., 1985) and EtOH induced locomotor activity in mice (Escarabajal et al., 2000). However, triazole has also been shown to cause a non-specific reduction in the consumption of saccharin-quinine solution (Rotzinger et al., 1994) and food intake (Tampier et al., 1995). Such data bring into question whether a reduction in $\mathrm{EtOH}$ consumption is a function of reduced ACD production or a general reduction in consummatory behavior caused by triazole. Recent studies have utilized a somewhat different approach to limiting the activity of the catalase system. The hydrogen peroxide $\left(\mathrm{H}_{2} \mathrm{O}_{2}\right)$ scavenging compounds ebselen and alpha lipoic acid inhibit the formation of ACD through their reduction in the catalase $-\mathrm{H}_{2} \mathrm{O}_{2}$ reaction and subsequent formation of Compound I (Cohen et al., 1980). Ledesma and colleagues have demonstrated that exposure to both ebselen or alpha lipoic acid inhibit EtOH-stimulated locomotor activity in mice (Ledesma et al., 2012; Ledesma and Aragon, 2013). 
Unlike compounds that directly affect brain catalase activity, thiol amino acid compounds, such as D-penicillamine or L-cysteine act to sequester ACD into a non-reactive stable adduct without altering EtOH metabolism (Cederbaum and Rubin, 1976; Nagasawa et al., 1978). Several studies have been conducted using these compounds which have added support for the role of $\mathrm{ACD}$ in the behavioral and pharmacological actions of EtOH. For instance, administration of either D-penicillamine or L-cysteine effectively reduced $\mathrm{EtOH}$ consumption and decreased EtOH conditioned place preference (CPP) in rats (Font et al., 2006b; Diana et al., 2008; Peana et al., 2008). Intra-cisterna magna injections of D-pennicillamine acted to block EtOH- and/or ACD appetitive conditioning to a surrogate nipple in newborn rats (March et al., 2013) and induced locomotor activity and tactile stimulus preference in preweanling rats (Pautassi et al., 2011). Mice exhibit a decrease in EtOH CPP and a reduction in $\mathrm{EtOH}$-induced motor depression when treated with D-penicillamine (Font et al., 2005, 2006a). L-cysteine has been found to reduce nose-poke responding for $\mathrm{ACD}$ and $\mathrm{EtOH}$ during acquisition, maintenance, and reinstatement phases of testing (Peana et al., 2010, 2012) as well as inhibit EtOH and ACD induced CPP (Peana et al., 2009). Peripheral and central (intra-VTA) exposure to D-penicillamine significantly reduced expression of the alcohol-deprivation effect (ADE) as observed by a lack on an increase in EtOH consumption during the initial 3 post-abstinence measurements (Orrico et al., 2013). This finding offers support for the role of ACD in the expression of relapse-like behaviors as the ADE has been established as an animal model for EtOH relapse-drinking (for review see: McBride and Li, 1998).

Perhaps the most compelling evidence for the involvement of ACD in the central actions of EtOH has emerged from studies utilizing adenoviral and lentiviral vectors that alter catalase, $\mathrm{ADH}$, or ALDH activity. Approximating the significantly higher activity of the $\mathrm{ADH}$ enzyme for individuals expressing the ADH1B*2 gene, mutated cDNA which encoded $\mathrm{rADH}-47 \mathrm{His}$ (the rat analogue for the ADH1B*2 gene) was peripherally administered to the University of Chile Bibulous (UChB) alcohol preferring rat line and resulted in significantly higher ACD blood levels while also significantly reducing EtOH consumption (RiveraMeza et al., 2010, 2012). Similarly, an adenoviral vector coded for ALDH2 antisense RNA, to approximate clinical condition of reduced ALDH2 activity, produced comparable increases in blood ACD levels and decreases in EtOH consumption (Ocaranza et al., 2008; Rivera-Meza et al., 2012). Studies looking at the central administration of anticatalase (shRNA)- or ADH (rADH1)encoding lentiviral vectors, which inihibit catalase synthesis or increases the activity of $\mathrm{ADH}$ respectively, have been found to alter EtOH-related behaviors. Administration of the anticalatase lentiviral vector into the ventral tegemental area (VTA) significantly reduced $\mathrm{EtOH}$ consumption and $\mathrm{EtOH}$ stimulated DA release in the AcbSh whereas the $\mathrm{AADH} 1$-encoding vector facilitated an increase in EtOH intake (Karahanian et al., 2011). Quintanilla et al. (2012) reported that insertion of an anticatalase viral vector into the VTA resulted in the reduction of $\mathrm{EtOH}$ consumption when administered prior to EtOH testing. However, when the viral vector was administered during an ongoing $\mathrm{EtOH}$ drinking period, animals only exhibited a reduction in $\mathrm{EtOH}$ intake following a period of imposed abstinence during relapse-like drinking (Quintanilla et al., 2012). With regard to $\mathrm{ADE}$ expression, an additional study examining the effects of intra-VTA injection of anticatalase viral vector immediately following 67 consecutive days of $\mathrm{EtOH}$ exposure and immediately prior to a 15 day $\mathrm{EtOH}$ deprivation period, significantly reduced relapse drinking during both a first and second reinstatement of EtOH access (Tampier et al., 2013). Taken as a whole, research utilizing such cutting-edge techniques suggest that ACD possess a substantial role in the neurobiological actions of EtOH.

\section{ACD EXHIBITS REWARDING PROPERTIES}

While it is difficult to suggest that the behavioral and neurobiological effects of EtOH are completely dependent on the presence of ACD, there is a substantial amount of literature suggesting that ACD is involved to a significant extent. Studies examining the behavioral effects of ACD, with regard to EtOH reward, have reported that intra-cranial ventricular (ICV) administration of ACD acted to increase the consumption of and preference for EtOH in rodents (Brown et al., 1979, 1980; Amit and Smith, 1985) while peripheral administration of higher doses of ACD produced a conditioned taste aversion in several rat lines (Brown et al., 1978; Aragon et al., 1986; Kunin et al., 2000; Quintanilla et al., 2002; Escarabajal et al., 2003). Utilizing the UChB rat line (an alcohol preferring rat line), researchers have revealed that peripheral ACD exposure, at lower doses (50$100 \mathrm{mg} / \mathrm{kg}$ ACD) than those shown to produce a conditioned taste aversion ( $>200 \mathrm{mg} / \mathrm{kg} \mathrm{ACD}$ ), acted to significantly increase the consumption of EtOH over the two weeks following ACD administration (Tampier and Quintanilla, 2002). Taken together, such findings may suggest that ACD facilitates the development of tolerance to the aversive effects of $\mathrm{EtOH}$ thereby increasing $\mathrm{EtOH}$ consumption.

It has also been reported that ACD possesses rewarding/reinforcing properties itself as animals readily self-administered both ICV ACD (Amit et al., 1977; Brown et al., 1979, 1980) and intra-venous ACD (Myers et al., 1984a,b; Takayama and Uyeno, 1985). Central ICV administration of ACD produced a CPP (Smith et al., 1984). Extending on such findings, recent endeavors have reported that ACD, whether administered centrally or peripherally, produced a CPP in several rat lines (Quintanilla and Tampier, 2003; Peana et al., 2008; Spina et al., 2010). Adult rats peripherally treated with ACD exhibit a dose-dependent preference to a discrete olfactory stimulus (Quertemont and DeWitte, 2001). Rat pups exhibited a significant preference to an olfactory cue previously paired with ACD exposure (March et al., 2013) while pre-weanling rats exhibited an ACD-dependent stimulation of locomotor activity and tactile stimulus preference following $\mathrm{EtOH}$ administration (Nizhnikov et al., 2007; Pautassi et al., 2011). ACD has been shown to dose-dependently alter locomotor activity in adult animals as well. Rodent testing has reported that the central administration of lower doses of ACD resulted in significant increase in locomotor activty (Correa et al., 2003; SanchezCatalan et al., 2009) while higher doses, administered either centrally or peripherally, resulted in a significant depression 
of locomotor activity (Holtzman and Schneider, 1974; Ortiz et al., 1974; Myers et al., 1987; Durlach et al., 1988; Quertemont et al., 2004; Tambour et al., 2006). An early study also observed comparable biphasic effects utilizing a vapor exposure paradigm to deliver ACD (Ortiz et al., 1974). Recent studies have pursued the evaluation of the reinforcing effects of ACD via the oral route and reported that rats will actively nose-poke (Peana et al., 2010, 2012) or lever press to obtain ACD (Cacace et al., 2012). However, it is unlikely that the effects of oral ACD on the ACD self-administration were mediated via central ACD as Peana et al. $(2010,2012)$ reported that blood and brain ACD levels did not significantly differ between rats consuming oral ACD and those consuming water (Peana et al., 2010, 2012). Nonetheless, ACD possess rewarding properties itself which are related to (or underlie) the behavioral actions of EtOH.

\section{ACETALDEHYDE REACTIVITY: BYPRODUCTS OF ACETALDEHYDE}

Acetaldehyde is a highly reactive compound that interacts with several endogenous neurochemicals in the brain to form a number of additional biologically active products (Cohen and Collins, 1970; Davis and Walsh, 1970; Walsh et al., 1970; Cohen, 1976). With regard to neurobiological and behavioral testing of the byproducts of $\mathrm{ACD}$, the majority of attention has focused on two main classes of compounds which are formed through condensation of ACD with the catecholamines. The first class of compounds, the tetrahydroisoquinoline alkaloids (THIQs), are formed through both the direct and indirect condensation of ACD with the monoamines: dopamine, epinephrine, and norepinephrine (Cohen, 1976). The tetrahydro-beta-carbolines (TBCs) on the other hand, are formed through the reaction of ACD with the indoleamines: tryptophan and tryptamine (Buckholtz, 1980). The THIQs tetrahydropapaveroline (THP) and salsolinol (SAL) have received the most attention as to their role in alcohol use-disorders as both compounds can be detected in the brain following EtOH administration. The TBCs have received considerably less attention and contradictory data exists as to their contribution to the neurobiological effects of EtOH.

\section{TETRAHYDROPAPAVEROLINE}

The formation of THP occurs via the condensation of dopaldehyde and dopamine. In this sense, ACD is indirectly associated with the formation of THP as ACD inhibits the breakdown/metabolization of dopaldehyde subsequently increasing THP levels in the brain (Davis and Walsh, 1970). Early studies observed an enhanced preference for $\mathrm{EtOH}$ and consumption of $\mathrm{EtOH}$ following ICV microinjections of low concentrations of THP in both rodents and primates (Melchior and Myers, 1977; Myers and Melchior, 1977; McCoy et al., 2003) while higher concentrations reduced both EtOH consumption and preference (Duncan and Deitrich, 1980). Manipulation of the mesolimbic DA pathway through microinjections of lower doses of THP into either the ventral tegmental area (VTA) or Nucleus Accumbens (Acb) accentuated $\mathrm{EtOH}$ preference in rats (Myers and Privette, 1989; Duncan and Fernando, 1991). Experiments were conducted in an effort to identify the neuroanatomical substrates of both the enhancing and aversive properties of THP with regard to alcohol related behaviors (Privette et al., 1988; Myers and Privette, 1989; Privette and Myers, 1989) however, research on the role of THP in $\mathrm{EtOH}$-use disorders has slowed considerably over the past two decades.

\section{SALSOLINOL}

Salsolinol (SAL; 1-methyl-6,7-dihydroxy-1,2,3,4-tetrahydroisoquinoline) is the most extensively studied byproduct of ACD in relation to $\mathrm{EtOH}$-use disorders and studies aimed at examining the underlying contribution of SAL to the reinforcing properties of EtOH are still in full swing. The in vivo formation of SAL occurs primarily through non-enzymatic Pictet-Spengler condensation of DA with ACD (Lee et al., 2010) but has been hypothesized to occur through secondary processes as well (for review see: Hipolito et al., 2012). Several studies have sought to quantify SAL levels within the body and brain following $\mathrm{EtOH}$ ingestion with mixed results. Specifically in the rodent brain, studies have shown that EtOH exposure (via oral consumption or experimenter administered EtOH) increased (Rojkovicova et al., 2008) or did not alter (Lee et al., 2010) SAL levels in several brain regions. Nonetheless, there is a substantial amount of evidence suggesting that SAL is intricately involved with the rewarding properties of EtOH.

While the effect of SAL administration on EtOH intake received considerably less attention than that of ACD, early endeavors found that centrally ICV administered SAL caused animals to exhibit an increase in both their consumption of and preference for (Myers and Melchior, 1977; Duncan and Deitrich, 1980; Purvis et al., 1980). Altshuler and Shippenberg (1982) indicated that SAL possess similar discriminative properties compared to EtOH in that animals respond comparably when SAL is substituted for EtOH. More recently, several laboratories have shown that SAL exhibits reinforcing properties in the absence of EtOH. Animals exhibited a CPP for peripheral injections of $10 \mathrm{mg} / \mathrm{kg} \mathrm{SAL}$ with higher $(30 \mathrm{mg} / \mathrm{kg}$ ) and lower $(1$ and $3 \mathrm{mg} / \mathrm{kg}$ ) doses falling in a $\mathrm{U}$-shaped dose response curve (Matsuzawa et al., 2000). Interestingly, when the animals were exposed to a conditioned fear stress (foot shock) the dose response curve shifted to the left (optimal dose: $3 \mathrm{mg} / \mathrm{kg}$ ) as the animals exhibited a greater sensitivity to the reinforcing properties of SAL (Matsuzawa et al., 2000). Central administration of SAL (intra-VTA) has also been shown to induce a CPP in rats (Hipolito et al., 2011). Much like in response to $\mathrm{EtOH}$, rats will exhibit a biphasic response in SAL-stimulated locomotor activity, specifically when SAL is microinjected into the VTA (Hipolito et al., 2010). Perhaps the most convincing evidence that SAL is reinforcing, even in the absence of EtOH, lies in data showing that animals will readily self-administer SAL into the posterior (p)VTA via intra-cranial self-administration at concentrations far below required to sustain the ICSA or EtOH or ACD (Rodd et al., 2008). Thus, research has outlined a clear role for SAL in the behavioral and neurobiological actions of EtOH and ongoing research is working toward the delineation of the nature of this contribution.

\section{TETRAHYDRO-BETACARBOLINES}

The role of TBCs in EtOH-use disorders has received considerably less attention than ACD and/or SAL. Findings have been 
somewhat inconsistent as early research indicated that peripheral injections of TBC derivatives reduced EtOH preference (Geller and Purdy, 1975). Central administration (ICV microinjections) of the TBC tryptoline had the opposite effect as it significantly increased both $\mathrm{EtOH}$ preference and $\mathrm{EtOH}$ consumption (Myers and Melchior, 1977; Tuomisto et al., 1982; Airaksinen et al., 1983; Huttunen and Myers, 1987; Adell and Myers, 1994). Co-administration THP and tryptoline resulted in a synergistic increase in EtOH preference and consumption (Myers and Oblinger, 1977). Hippocampal microinjections of TBCs produced alterations in both 5-HT and norepinephrine levels thereby significantly augmenting EtOH preference and consumption in low alcohol drinking (LAD) rats (Huttunen and Myers, 1987; Adell and Myers, 1995). Additionally, TBCs have been shown to possess an affinity for the delta opioid receptor (Airaksinen et al., 1984). Overall, however, the pharmacological properties of TBCs have yet to be fully examined.

\section{THE NEUROBIOLOGICAL ACTIONS OF EtOH AND EtOH METABOLITES WITHIN THE REWARD PATHWAY}

While early studies investigated the effects of the central and/or peripheral administration of ACD and/or SAL on the behavioral actions of $\mathrm{EtOH}$ (as discussed above), the dissemination of the underlying mechanisms of ACD and SAL at the neurobiological level has gained significant traction over the past three decades. The advent of a number of novel techniques (i.e., intracranial self-administration; ICSA) has allowed researchers to more thoroughly evaluate the neurobiological actions of drugs of abuse including $\mathrm{EtOH}$ and its metabolites. Research to date suggests that the neurobiological actions of EtOH and $\mathrm{EtOH}$ metabolites overlap to ultimately affect the development/expression of EtOHuse disorders. This section will present an overview of preclinical research focused on the neurobiological mechanisms within the brain reward pathway that have been identified to play a key role in the rewarding/reinforcing properties of EtOH, ACD, and the THIQs.

Numerous studies have implicated the mesocorticolimbic dopamine reward pathway (MCL) as a key mediator of the rewarding/reinforcing properties of virtually every major drug of abuse including EtOH (for review see: Di Chiara and Imperato, 1988). The MCL originates in the VTA and projects to several forebrain regions including the Acb (Oades and Halliday, 1987). An early study indicated that peripheral EtOH exposure stimulated DA neuronal activity within the substantia nigra (Mereu et al., 1984). A subsequent experiment found that peripheral injections of $\mathrm{EtOH}(0.5 \mathrm{mg} / \mathrm{kg})$ significantly elevated DA levels within the AcbSh of freely moving rats (Di Chiara and Imperato, 1985). Subsequent research over the past 3 decades has elucidated a cascade of neurochemical events within the MCL that underlie EtOH reinforcement (for review see: Spanagel, 2009). For instance, it has been well documented that $\mathrm{EtOH}$ itself primarily targets N-methyl-D-aspartate (NMDA; Lovinger et al., 1989), 5-hydroxytryptamine 3 (5- $\mathrm{HT}_{3}$; Lovinger and Zhou, 1998), nicotinic acetylcholine (nAch; Narahashi et al., 1999), $\gamma$-aminobutyric acid $A\left(G_{A B A}\right)$ and glycine (Mihic et al., 1997; Mihic, 1999) receptors. The EtOH molecule also primarily interacts with non-ligand gated ion channels as $\mathrm{EtOH}$ inhibits L-type $\mathrm{Ca}^{2+}$ channels and opens $\mathrm{G}$ protein-activated inwardly rectifying $\mathrm{K}^{+}$(GIRKs) channels (Vengeliene et al., 2008). Overall, such primary effects underlie and/or contribute to several secondary effects within the MCL (i.e., increases in DA efflux) that ultimately result in the rewarding/reinforcing properties of EtOH (Spanagel, 2009). Thus, research has established that the neurobiological actions of the EtOH molecule itself are important to the reinforcing properties of EtOH. However, given the dynamic nature of the neurobiological functioning of the MCL and the concurrent actions of EtOH metabolites, the extent to which the actions of the $\mathrm{EtOH}$ molecule itself contribute to overall EtOH reinforcement is somewhat tenuous.

Several studies have focused on the role of the projection from the VTA to the Acb in the neurobiological actions of EtOH as well as the metabolites of EtOH (see Figure 2). Specifically within the VTA, EtOH and ACD have been shown to activate DA neurons by significantly increasing their firing rate (Gessa et al., 1985; Brodie et al., 1990; Foddai et al., 2004), albeit through differing mechanisms (for review see: Deehan et al., 2013). Sequestering ACD formation through the direct infusion of D-penicillamine into the VTA inhibits DA neuronal activation by the intra-gastric administration of both EtOH and ACD (Enrico et al., 2009). Local application of an ADH (Foddai et al., 2004) or catalase inhibitor (Melis et al., 2007; Diana et al., 2008) in the VTA prevents EtOH stimulated increases in DA neuronal activity. These findings coupled with data from in vitro studies showing that ACD stimulates VTA DA neuronal activity at concentrations 1200-2000 fold lower than that required for EtOH suggest that ACD is critical component required for EtOH stimulated DA activity within the VTA (Brodie and Appel, 1998; Brodie et al., 1999; Diana et al., 2008). A recent paper has reported that SAL is also capable of stimulating VTA DA neuronal activity at concentrations 10-1,000 fold lower than the lowest effective concentration of ACD (Xie et al., 2012a).

Relative differences in effective concentrations between EtOH, ACD, and SAL have also been reported by studies examining the behavioral neuropharmacology of these compounds within the VTA. An early study indicated the alcohol preferring (P) rats (an animal model for alcoholism) would readily self-adminster EtOH directly into the VTA exhibiting a U-shaped dose response curve with $100 \mathrm{mg} \%$ being the most effective concentration (Gatto et al., 1994). Follow-up studies identified a regional heterogeneity within the VTA as both $\mathrm{P}$ and Wistar rats would self-administer EtOH into the posterior (p) VTA but not anterior (a) VTA at doses of 20-80 mM (Rodd et al., 2003, 2005). Much like EtOH, both ACD and SAL are self-administered into the pVTA in an inverted U-shaped dose response pattern and in congruence with neurophysiological data, the pVTA appears to be significantly more sensitive to the rewarding/motivational properties of each compound in a stepwise fashion (SAL > $\mathrm{ACD}>\mathrm{EtOH})$. For example, $\mathrm{P}$ rats self-administered ACD between the dose ranges of $6-90 \mu \mathrm{M}$ (Rodd-Henricks et al., 2002; Rodd et al., 2005) whereas SAL ICSA was supported in a dose range of $0.03-0.3 \mu \mathrm{M}$ (Rodd et al., 2008). For perspective, 


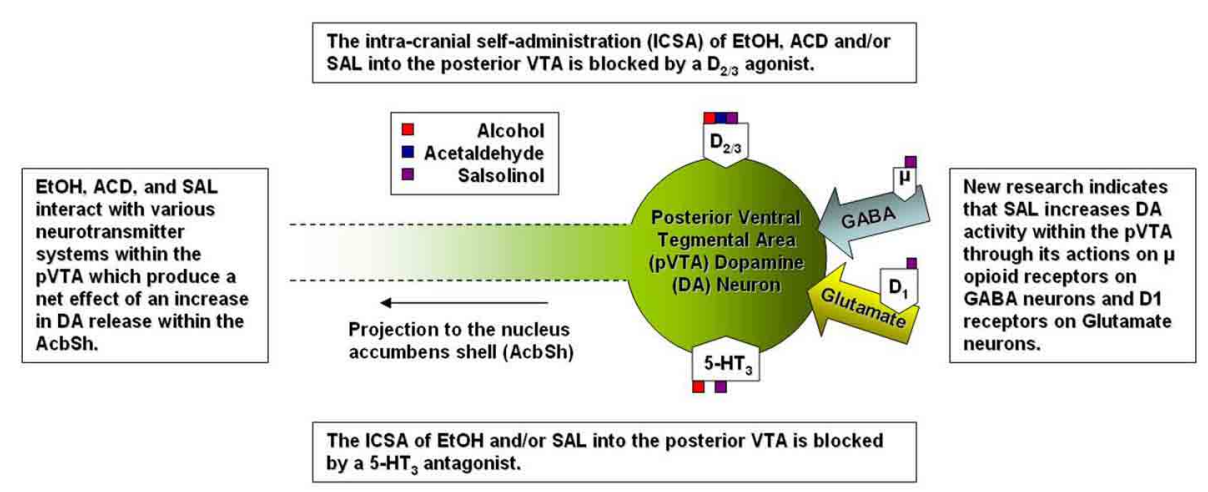

FIGURE 2 | A simplified representation of the sites of action for alcohol and alcohol metabolites on posterior ventral tegmental area dopamine neurons.

the optimal concentration for the ICSA of SAL is approximately 200 -fold lower than the most effective concentration of $\mathrm{ACD}$ and $300 \times 10^{3}$ lower than the optimal concentration of EtOH. Additionally, the co-infusion of the $\mathrm{D}_{2 / 3}$ agonist quinpirole $(100 \mu \mathrm{M})$ blocked the ICSA of EtOH, ACD, and SAL into the pVTA (Rodd et al., 2005, 2008) suggesting that of DA neuronal activation within the pVTA is a common mechanism underlying the rewarding/motivational properties of $\mathrm{EtOH}, \mathrm{ACD}$, and SAL.

An alternative method to assess the efficacy of a given compound to stimulate DA neurons within the VTA involves microinjecting the compound into the VTA and measuring DA release in downstream projection structures (i.e., the Acb). An early study employed such a paradigm to examine the down-stream effects of microinjections of THP into the VTA on DA efflux within the core $(\mathrm{AcbC})$ and the AcbSh reporting that a $13.6 \mu \mathrm{M}$ microinfusion of THP increased DA efflux in the AcbC (94\%) whereas the same dose decreased DA efflux in the AcbSh (51\%; Myers and Robinson, 1999). Given that cannula placement were anterior to the VTA and the THP dose was well above the pharmacological range of the in vivo generation of THP (Haber et al., 1997; Baum et al., 1999), it is difficult to resolve whether THP altered DA neuronal activity directly or through a non-specific mechanism. Recent research, however, has utilized similar equipment as that employed for ICSA experiments to examine the effects of intra-pVTA microinjections of EtOH, ACD, and/or SAL on DA levels downstream within the AcbSh (Ding et al., 2009, 2011; Deehan et al., 2013). Ding et al. (2009) reported that pulse microinjections of $200 \mathrm{mg} \%(\sim 44 \mathrm{mM})$ EtOH was the most efficacious dose at stimulating DA efflux in the AcbSh of Wistar rats. Utilizing the same range of doses of ACD and SAL that were reliably self-administered via ICSA (Rodd et al., 2005, 2008), Deehan et al. (2013) reported that Wistar rats exhibited comparable U-shaped dose response curves for DA efflux in the AcbSh following pulse microinjections of ACD and/or SAL into the pVTA. Along the same lines as previous observations utilizing alternative paradigms, DA neurons within the pVTA exhibited a significantly greater sensitivity to ACD and/or SAL compared to EtOH. Pulse microinjections of $23 \mu \mathrm{M}$ ACD or
$0.3 \mu \mathrm{M}$ SAL were effective at significantly increasing DA efflux within the AcbSh to levels 200 and 300\% above baseline respectively (Deehan et al., 2013). Moreover, this was observed for an ACD dose that was over 1800 fold, and a SAL dose that was 147,000 fold lower, than the peak dose of EtOH. These data further suggest that the pVTA is differentially sensitive to $\mathrm{EtOH}, \mathrm{ACD}$, and SAL in a manner that is consistent with the production of ACD and SAL through conventional metabolic processes.

The findings from the microinjection/microdialysis study by Deehan et al. (2013) extend on previous research that reported increases in accumbal DA in response to local exposure of higher concentrations of ACD or SAL within the pVTA. The reverse microdialysis of $75 \mu \mathrm{M}$ ACD in the pVTA stimulated DA release in the AcbSh to $150 \%$ of baseline (Melis et al., 2007; Diana et al., 2008) while Hipolito et al. (2011) reported that a microinjection of SAL $(150 \mu \mathrm{M})$ within the pVTA caused an increase in AcbSh DA to $130 \%$ of baseline. However, SAL has been shown to modulate DA levels within the AcbC and AcbSh in an opposing manner. Local perfusion of SAL via reverse microdialysis, over the course of a 20-min sample, significantly increased DA levels in the AcbC but decreased DA levels in the AcbSh (Hipolito et al., 2009) in a manner consistent with the effects of selective $\mu$ - and $\delta$-opioid receptor agonists reported by the same lab (Hipolito et al., 2008). Although the lowest concentration of SAL $(5 \mu \mathrm{M})$ used by Hipolito et al. (2009) was significantly higher than the optimal concentration $(0.3 \mu \mathrm{M})$ that stimulated activity in DA neurons within the pVTA (Deehan et al., 2013), ICSA studies have shown that the AcbSh is significantly less sensitive to the rewarding properties of SAL with the greatest level of responding exhibited for the $3.0 \mu \mathrm{M}$ concentration of SAL (Rodd et al., 2003). Additionally, the rewarding properties of SAL within the AcbSh were found to be dependent on post-synaptic activation of DA receptors as the $\mathrm{D}_{2 / 3}$ antagonist (sulpiride) completely abolished ICSA responding for SAL.

Overall, there are several neurobiological mechanisms that underlie the $\mathrm{EtOH}, \mathrm{ACD}$, or SAL induced stimulation of DA neuronal activity within the PVTA, not all of which participate 
equally across the three compounds. For instance, research has implicated $5-\mathrm{HT}_{3}$ receptors in the reinforcing properties of $\mathrm{EtOH}$ and SAL but not ACD. The compound ICS 250,390 (a 5- $\mathrm{HT}_{3}$ receptor antagonist) selectively prevents the ICSA of both $\mathrm{EtOH}$ and SAL but does not affect the ICSA of ACD (Rodd et al., 2005, 2008). This stands to reason as EtOH possesses an affinity for 5$\mathrm{HT}_{3}$ receptors (Lovinger and White, 1991) and SAL increases the efflux of 5-HT within the rat striatum (Maruyama et al., 1993) but ACD does not exhibit an affinity for $5 \mathrm{HT}_{3}$ receptors ( $\mathrm{Li}$, 2000). Within the striatum SAL decreases the metabolization of 5-HT through a reduction in metabolizing enzymes resulting in an increase in 5-HT levels to 20 times that of DA (Nakahara et al., 1994). Similar findings have been reported with regard to DA as SAL increases catecholamine levels within the brain through a combination of the inhibition of reuptake (Heikkila et al., 1971; Tuomisto and Tuomisto, 1973; Alpers et al., 1975) and a reduction in the metabolizing enzymes such as catecholmethyltransferase and monoamine oxidase (Collins et al., 1973; Alpers et al., 1975).

From early on, studies had outlined a substantial role for the $\mathrm{mu}$ opioid receptor (MOR) in the neurobiological actions of EtOH, ACD, and SAL within the MCL. Naltrexone, a general opioid antagonist with an affinity for all three opioid receptors (mu, delta and kappa), has been approved by the FDA for use in the treatment of alcohol use disorders (Johnson and Ait-Daoud, 2000). Preclinical data indicate that naltrexone decreases both free-choice consumption and the operant self-administration of $\mathrm{EtOH}$ (for review see: Gianoulakis, 2009). For instance, EtOH has been found to directly alter the release of opioid peptides (Jarjour et al., 2009) and both naltrexone and $\beta$-funaltrexamine ( $\beta$-FNA; a selective MOR antagonist) reduced the duration of DA release within the AcbSh caused by intra-VTA microinjections of EtOH (Valenta et al., 2013). Microinjections of higher concentrations of EtOH into the VTA stimulate locomotor activity that is prevented by the co-administration of $\beta$-FNA (Sanchez-Catalan et al., 2009) or the co-administration of D-penicillamine (Marti-Prats et al., 2010) suggesting that the locomotor activating effects of $\mathrm{EtOH}$ within the VTA require MOR activation as well as the presence of ACD.

Both ACD and SAL possess locomotor stimulating properties within the VTA and much like $\mathrm{EtOH}$, the activation of locomotor activity has been reported to be dependent on MOR activation (Sanchez-Catalan et al., 2009; Hipolito et al., 2011). To date, there is a lack of research investigating the effects of MOR manipulation on the self-administration of ACD or SAL. An early study observed a decrease in the IV self-administration of ACD when animals were treated with naloxone (Myers et al., 1984a). Further, the oral self-administration (nose poke responding) of ACD was decreased by naltrexone and naloxonazine (a selective $\mathrm{MOR}_{1}$ antagonist; Peana et al., 2011). Naltrexone also acted decrease extracellular signal-regulated kinase phosphorylation within the Acb caused by ACD self-administration (Peana et al., 2011). However, the full transgression from MOR activity to increased DA neuronal activity within the pVTA, and subsequent increase in DA release downstream, is indeed complex. Xie and colleagues have reported that SAL stimulates DA neurons within the pVTA indirectly by activating MORs which in turn inhibit of gama-amino butyric acid (GABA) neurons (Xie et al., 2012a) while also increasing glutamatergic signaling into the pVTA (Xie and Ye, 2012b). Overall, it is likely that the rewarding/reinforcing properties of both ACD and SAL in the pVTA are dependent on DA release within the AcbSh and the DA activity is modulated via MORs. After all it has been shown that direct stimulation of MORs increase DA release within the AcbSh (Spanagel et al., 1992) an similar effect to that observed following microinjections of $\mathrm{EtOH}$, ACD, or SAL into the pVTA (Ding et al., 2009; Deehan et al., 2013). Although there are no studies focused on the role of MOR activity in the central self-administration of ACD and/or SAL, the current body of literature has implicated MOR activity within the pVTA as a key mediator of the neurobiological action of ACD and/or SAL on DA neurons. Future research will help to further elucidate other contributory structures and neurochemical systems, within the MCL, with regard to ACD and SAL.

\section{GENERAL SUMMARY}

The action of EtOH within the CNS is extremely complex yet the current body of literature has outlined a significant role for ACD and SAL in the modulation of the behavioral and neurological effects of EtOH. It has been shown that EtOH can act directly within the VTA to stimulate DA neurons (Gessa et al., 1985; Lovinger and White, 1991; Brodie et al., 1999; Ye et al., 2001) and accumulating evidence suggests that both ACD and SAL exhibit distinct actions on neurobiological processes within the MCL. The utilization of inhibitory/sequestering agents preventing the conversion from EtOH into ACD clearly affect EtOH consumption and reinforcement further supporting the role for the metabolites of EtOH in EtOH-use disorders. Thus, convergent evidence supports the following assertions: (1) within the $\mathrm{CNS}, \mathrm{EtOH}$ is capable of altering neurobiological and behavioral processes, (2) evidence exists supporting the notion that the actions of EtOH, are, in part, mediated by the metabolites ACD and SAL formed during metabolic processes, (3) both ACD and SAL possess reinforcing properties within the MCL at levels shown to be pharmacologically relevant, and (4) further research focused on examining the central effects of $\mathrm{EtOH}$ and $\mathrm{EtOH}$ metabolites will greatly improve our understanding of how these compounds function in regard to the development/expression of EtOH-use disorders. Overall, the manifestation of EtOH-use disorders in the clinical population is undoubtedly a result of a complex and interrelated series of central and peripheral effects of EtOH and the metabolites of EtOH. Research aimed at increasing our understanding of such a complex system will facilitate the development of successful pharmaocterapeutic treatments for individuals suffering from, or are at a high risk to develop, an EtOH-use disorder.

\section{ACKNOWLEDGMENTS}

A portion of the research discussed was supported by the National Institutes of Health grants: AA007462, AA007611, and AA014437 from the National Institute on Alcohol Abuse and Alcoholism. 


\section{REFERENCES}

Adell, A., and Myers, R. D. (1994). Increased alcohol intake in low alcohol drinking rats after chronic infusion of the beta-carboline harman into the hippocampus. Pharmacol. Biochem. Behav. 49, 949-953. doi: 10.1016/0091-3057(94)90248-8

Adell, A., and Myers, R. D. (1995). 5-HT, dopamine, norepinephrine, and related metabolites in brain of low alcohol drinking (LAD) rats shift after chronic intrahippocampal infusion of harman. Neurochem. Res. 20, 209-215. doi: 10.1007/BF00970546

Airaksinen, M. M., Mahonen, M., Tuomisto, L., Peura, P., and Eriksson, C. J. (1983). Tetrahydrobeta-carbolines: effect on alcohol intake in rats. Pharmacol. Biochem. Behav. 18(Suppl. 1), 525-529. doi: 10.1016/0091-3057(83)90230-7

Airaksinen, M. M., Saano, V., Steidel, E., Juvonen, H., Huhtikangas, A., and Gynther, J. (1984). Binding of beta-carbolines and tetrahydroisoquinolines by opiate receptors of the delta-type. Acta Pharmacol. Toxicol. (Copenh) 55, 380-385. doi: 10.1111/j.16000773.1984.tb01998.x

Alpers, H. S., McLaughlin, B. R., Nix, W. M., and Davis, V. E. (1975). Inhibition of catecholamine uptake and retention in synaptosomal preparations by tetrahydroisoquinoline and tetrahydroprotoberberine alkaloids. Biochem. Pharmacol. 24, 1391-1396. doi: 10.1016/0006-2952(75)90361-5

Altshuler, H. L., and Shippenberg, T. S. (1982). Tetrahydroisoquinoline and opioid substrates of alcohol actions. Prog. Clin. Biol. Res. 90, 329-344.

Amit, Z., Brown, Z. W., and Rockman, G. E. (1977). Possible involvement of acetaldehyde, norepinephrine and their tetrahydroisoquinoline derivatives in the regulation of ethanol self-administration. Drug Alcohol Depend. 2, 495-500. doi: 10.1016/0376-8716(77)90049-7

Amit, Z., and Smith, B. R. (1985). A multi-dimensional examination of the positive reinforcing properties of acetaldehyde. Alcohol 2, 367-370. doi: 10.1016/0741-8329(85)90077-1

Aragon, C. M., Abitbol, M., and Amit, Z. (1986). Acetaldehyde may mediate reinforcement and aversion produced by ethanol. An examination using a conditioned taste-aversion paradigm. Neuropharmacology 25, 79-83. doi: 10.1016/0028-3908(86)90062-6

Aragon, C. M., and Amit, Z. (1992). The effect of 3-amino-1 2, 4-triazole on voluntary ethanol consumption: evidence for brain catalase involvement in the mechanism of action. Neuropharmacology 31, 709-712. doi: 10.1016/0028-3908 (92) $90150-\mathrm{N}$

Aragon, C. M., Spivak, K., and Amit, Z. (1985). Blockade of ethanol induced conditioned taste aversion by 3 -amino-1 2, 4 -triazole: evidence for catalase mediated synthesis of acetaldehyde in rat brain. Life Sci. 37, 2077-2084. doi: 10.1016/00243205(85)90579-X

Ball, D. (2008). Addiction science and its genetics. Addiction 103, 360-367. doi: 10.1111/j.1360-0443.2007.02061.x

Baum, S. S., Hill, R., Kiianmaa, K., and Rommelspacher, H. (1999). Effect of ethanol on (R)- and (S)Salsolinol, salsoline, and THP in the nucleus accumbens of AA and ANA rats. Alcohol 18, 165-169. doi: 10.1016/S0741-8329(98)00080-9

Brodie, M. S., and Appel, S. B. (1998). The effects of ethanol on dopaminergic neurons of the ventral tegmental area studied with intracellular recording in brain slices. Alcohol. Clin. Exp. Res. 22, 236-244. doi: 10.1111/j.15300277.1998.tb03644.x

Brodie, M. S., Pesold, C., and Appel, S. B. (1999). Ethanol directly excites dopaminergic ventral tegmental area reward neurons. Alcohol. Clin. Exp. Res. 23, 1848-1852. doi: 10.1111/j.15300277.1999.tb04082.x

Brodie, M. S., Shefner, S. A., and Dunwiddie, T. V. (1990). Ethanol increases the firing rate of dopamine neurons of the rat ventral tegmental area in vitro. Brain Res. 508, 65-69. doi: 10.1016/0006-8993 (90)91118-Z

Brown, Z. W., Amit, Z., and Rockman, G. E. (1979). Intraventricular selfadministration of acetaldehyde, but not ethanol, in naive laboratory rats. Psychopharmacology (Berl) 64, 271-276. doi: 10.1007/BF00427509

Brown, Z. W., Amit, Z., and Smith, B. (1980). Intraventricular selfadministration of acetaldehyde and voluntary consumption of ethanol in rats. Behav. Neural Biol. 28, 150-155. doi: 10.1016/S0163-1047(80)91487-9

Brown, Z. W., Amit, Z., Smith, B., and Rockman, G. E. (1978). Differential effects on conditioned taste aversion learning with peripherally and centrally administered acetaldehyde. Neuropharmacology 17, 931-935. doi: 10.1016/0028-3908 (78) $90134-\mathrm{X}$

Buckholtz, N. S. (1980). Neurobiology of tetrahydro-beta-carbolines. Life
Sci. 27, 893-903. doi: 10.1016/00243205(80)90098-3

Cacace, S., Plescia, F., Barberi, I., and Cannizzaro, C. (2012) Acetaldehyde oral selfadministration: evidence from the operant-conflict paradigm. Alcohol. Clin. Exp. Res. 36, 1278-1287. doi 10.1111/j.1530-0277.2011.01725.x

Carpenter, R. K., and Macleod, L. D. (1952). The effects of ethyl alcohol and acetaldehyde on maze behaviour and motor co-ordination in rats. J. Ment. Sci. 98, 167-173.

Cederbaum, A. I., and Rubin, E. (1976) Mechanism of the protective action of cysteine and penicillamine against acetaldehyde-induced mitochondrial injury. Biochem. Pharmacol. 25, 2179-2185. doi: 10.1016/0006-2952(76)90130-1

Chifflot, M. J. (1916). Sur un cas de rubefaction de la face, tendant a se generalizer a la suite de I'ngestion du Coprinus atramentarius. Fr. Bull. Soc. Mycol. France 32, 63.

Cohen, G. (1976). Alkaloid products in the metabolism of alcohol and biogenic amines. Biochem. Pharmacol. 25, 1123-1128. doi: 10.1016/00062952(76)90357-9

Cohen, G., and Collins, M. (1970). Alkaloids from catecholamines in adrenal tissue: possible role in alcoholism. Science 167, 1749-1751. doi 10.1126/science.167.3926.1749

Cohen, G., Sinet, P. M., and Heikkila, R. (1980). Ethanol oxidation by rat brain in vivo. Alcohol. Clin. Exp. Res. 4, 366-370. doi: 10.1111/j.15300277.1980.tb04833.x

Collins, A. C., Cashaw, J. L., and Davis, V. E. (1973). Dopaminederived tetrahydroisoquinoline alkaloids-inhibitors of neuroamine metabolism. Biochem. Pharmacol. 22, 2337-2348. doi: 10.1016/0006-2952(73)90015-4

Correa, M., Arizzi, M. N., Betz, A., Mingote, S., and Salamone, J. D. (2003). Open field locomotor effects in rats after intraventricular injections of ethanol and the ethanol metabolites acetaldehyde and acetate. Brain Res. Bull. 62, 197-202. doi: 10.1016/j.brainresbull.2003.09.013

Correa, M., Viaggi, C., Escrig, M. A., Pascual, M., Guerri, C., Vaglini, F. et al. (2009). Ethanol intake and ethanol-induced locomotion and locomotor sensitization in Cyp2el knockout mice. Pharmacogenet Genomics 19, 217-225. doi 10.1097/FPC.0b013e328324e726

Davis, V. E., and Walsh, M. J. (1970). Alcohol, amines, and alkaloids: a possible biochemical basis for alcohol addiction.
Science 167, 1005-1007. doi: 10.1126/science.167.3920.1005

Deehan, G. A. Jr., Brodie, M. S., and Rodd, Z. A. (2013). "What is in that drink: the biological actions of ethanol, acetaldehyde, and salsolinol," in Current Topics in Behavioral Neurosciences: Behavioral Neurobiology of Alcohol Addiction, eds W. H Sommer and R. Spanagel (Berlin, Heidelberg: Springer-Verlag), 163-184.

Deehan GA Jr., Engleman, E. A., Ding, Z. M., McBride, W. J.,and Rodd, Z. A. (2013). Microinjections of acetaldehyde or salsolinol into the posterior ventral tegmental area increase dopamine release in the nucleus accumbens shell. Alcohol. Clin. Exp. Res. 37, 722-729. doi: 10.1111/acer.12034

Di Chiara, G., and Imperato, A. (1985). Ethanol preferentially stimulates dopamine release in the nucleus accumbens of freely moving rats. Eur. J. Pharm. 115, 131-132. doi: 10.1016/0014-2999(85)90598-9

Di Chiara, G., and Imperato, A. (1988). Drugs abused by humans preferentially increase synaptic dopamine concentrations in the mesolimbic system of freely moving rats. Proc. Natl. Acad. Sci. U.S.A. 85, 5274-5278. doi: 10.1073/pnas.85.14.5274

Diana, M., Peana, A. T., Sirca, D., Lintas, A., Melis, M., and Enrico, P. (2008). Crucial role of acetaldehyde in alcohol activation of the mesolimbic dopamine system. Ann. N.Y. Acad. Sci. 1139, 307-317. doi 10.1196/annals.1432.009

Ding, Z. M., Oster, S. M., Hall, S. R., Engleman, E. A., Hauser S. R., McBride, W. J., et al. (2011). The stimulating effects of ethanol on ventral tegmental area dopamine neurons projecting to the ventral pallidum and medial prefrontal cortex in female Wistar rats: regional difference and involvement of serotonin-3 receptors. Psychopharmacology (Berl) 216, 245-255. doi: 10.1007/s00213-011-2208-5

Ding, Z. M., Rodd, Z. A., Engleman, E. A., and McBride, W. J. (2009). Sensitization of ventral tegmental area dopamine neurons to the stimulating effects of ethanol. Alcohol. Clin. Exp. Res. 33, 1571-1581. doi: $\quad 10.1111 / j .1530-0277$ 2009.00985.x

Duncan, C., and Deitrich, R. A. (1980). A critical evaluation of tetrahydroisoquinoline induced ethanol preference in rats. Pharmacol. Biochem. Behav. 13, 265-281. doi: 10.1016/0091-3057(80)90083-0 
Duncan, C. C., and Fernando, P. W. (1991). Effects of tetrahydropapaveroline in the nucleus accumbens and the ventral tegmental area on ethanol preference in the rat. Alcohol 8, 87-90. doi: 10.1016/07418329(91)91314-R

Durlach, J., Rinjard, P., Sprince, H., and Smith, G. G. (1988). Similar antagonistic effects of $\mathrm{Ca} \mathrm{N}$ acetylhomotaurinate on depression of motor activity and lethality induced by acetaldehyde or ethanol. Methods Find. Exp. Clin. Pharmacol. $10,437-447$.

Edenberg, H. J. (2011). Common and rare variants in alcohol dependence. Biol. Psychiatry 70, 498-499. doi: 10.1016/j.biopsych.2011.07.007

Ehlers, C. L., Liang, T., and Gizer, I. R. (2012). ADH and ALDH polymorphisms and alcohol dependence in Mexican and Native Americans. Am. J. Drug Alcohol Abuse 38, 389-394. doi: $\quad 10.3109 / 00952990.2012$. 694526

Enrico, P., Sirca, D., Mereu, M., Peana, A. T., Lintas, A., and Golosio, A., et al. (2009). Acetaldehyde sequestering prevents ethanolinduced stimulation of mesolimbic dopamine transmission. Drug Alcohol Depend. 100, 265-271. doi: 10.1016/j.drugalcdep.2008.10.010

Eriksson, C. J. (1977). Acetaldehyde metabolism in vivo during ethanol oxidation. Adv. Exp. Med. Biol. 85A, 319-341.

Eriksson, C. J., Hillbom, M. E., and Sovijarvi, A. R. (1980). Difficulties in measuring human blood acetaldehyde concentrations during ethanol intoxication. $A d v$. Exp. Med. Biol. 126, 439-451.

Escarabajal, M. D., De Witte, P., and Quertemont, E. (2003). Role of acetaldehyde in ethanol-induced conditioned taste aversion in rats. Psychopharmacology (Berl.) 167, 130-136.

Escarabajal, D., Miquel, M., and Aragon, C. M. (2000). A psychopharmacological study of the relationship between brain catalase activity and ethanol-induced locomotor activity in mice. J. Stud. Alcohol 61, 493-498.

Foddai, M., Dosia, G., Spiga, S., and Diana, M. (2004). Acetaldehyde increases dopaminergic neuronal activity in the VTA. Neuropsychopharmacology 29, 530-536. doi: 10.1038/sj.npp. 1300326

Font, L., Aragon, C. M., and Miquel, M. (2006a). Ethanol-induced conditioned place preference, but not aversion, is blocked by treatment with D-penicillamine, an inactivation agent for acetaldehyde. Psychopharmacology (Berl) 184, 56-64. doi: 10.1007/s00213-0050224-z

Font, L., Aragon, C. M., and Miquel, M. (2006b). Voluntary ethanol consumption decreases after the inactivation of central acetaldehyde by d-penicillamine. Behav. Brain Res. 171, 78-86. doi: 10.1016/j.bbr.2006.03.020

Font, L., Miquel, M., and Aragon, C. M. (2005). Prevention of ethanolinduced behavioral stimulation by D-penicillamine: a sequestration agent for acetaldehyde. Alcohol. Clin. Exp. Res. 29, 1156-1164. doi: 10.1097/01.ALC.0000171945 30494.AF

Frank, J., Cichon, S., Treutlein, J., Ridinger, M., Mattheisen, M., Hoffmann, P., et al. (2012). Genome-wide significant association between alcohol dependence and a variant in the $\mathrm{ADH}$ gene cluster. Addict. Biol. 17, 171-180. doi: $\quad 10.1111 / j .1369-1600.2011$. 00395.x

Gatto, G. J., McBride, W. J., Murphy, J. M., Lumeng, L., and Li, T. K. (1994). Ethanol self-infusion into the ventral tegmental area by alcoholpreferring rats. Alcohol 11, 557-564. doi: 10.1016/0741-8329(94)90083-3

Geller, I., and Purdy, R. (1975). Alteration of ethanol preference in rats; effects of beta-carbolines. $A d v$. Exp. Med. Biol. 59, 295-301.

Gessa, G. L., Muntoni, F., Collu, M., Vargiu, L., and Mereu, G. (1985). Low doses of ethanol activate dopaminergic neurons in the ventral tegmental area. Bran Res. 348, 201-203. doi: 10.1016/00068993(85)90381-6

Gianoulakis, C. (2009). Endogenous opioids and addiction to alcohol and other drugs of abuse. Curr. Top. Med. Chem. 9, 999-1015. doi: 10.2174/156802609789630956

Griffiths, P. J., Littleton, J. M., and Ortiz, A. (1974). Proceedings: chronic administration of acetaldehyde to mice: behavioural and biochemical similarities with chronic ethanol administration. $\mathrm{Br}$. J. Pharmacol. 50, 441P.

Haber, H., Roske, I., Rottmann, M., Georgi, M., and Melzig, M. F. (1997). Alcohol induces formation of morphine precursors in the striatum of rats. Life Sci. 60, 79-89. doi: 10.1016/S0024-3205 (96)00597-8

Hald, J., and Jacobsen, E. (1948). A drug sensitizing the organism to ethyl alcohol. Lancet 2, 1001-1004. doi: 10.1016/S0140-6736(48)91514-1
Hald, J., Jacobsen, E., and Larsen, V. (1949a). Formation of acetaldehyde in the organism in relation to dosage of antabuse (tetraethylthiuramdisulphide) and to alcohol-concentration in blood. Acta Pharmacol. Toxicol. (Copenh) 5, 179-188. doi: 10.1111/j.16000773.1949.tb03384.x

Hald, J., Jacobsen, E., and Larsen, V. (1949b). The rate of acetaldehyde metabolism in isolated livers and hind limbs of rabbits treated with antabuse (tetraethylthiuramdisulphide).

Acta Pharmacol. Toxicol. (Copenh) 5, 298-308. doi: 10.1111/j.16000773.1949.tb03395.x

Heikkila, R., Cohen, G., and Dembiec, D. (1971). Tetrahydroisoquinoline alkaloids: uptake by rat brain homogenates and inhibition of catecholamine uptake. J. Pharmacol. Exp. Ther. 179, 250-258.

Hipolito, L., Marti-Prats, L., SanchezCatalan, M. J., Polache, A., and Granero, L. (2011). Induction of conditioned place preference and dopamine release by salsolinol in posterior VTA of rats: Involvement of mu-opioid receptors. Neurochem. Int. 59, 559-562. doi: 10.1016/j.neuint. 2011.04.014

Hipolito, L., Sanchez-Catalan, M. J., Granero, L., and Polache, A. (2009). Local salsolinol modulates dopamine extracellular levels from rat nucleus accumbens: shell/core differences. Neurochem. Int. 55, 187-192. doi: 10.1016/j.neuint.2009.02.014

Hipolito, L., Sanchez-Catalan, M. J. Marti-Prats, L., Granero, L., and Polache, A. (2012). Revisiting the controversial role of salsolinol in the neurobiological effects of ethanol: old and new vistas. Neurosci. Biobehav. Rev. 36, 362-378. doi 10.1016/j.neubiorev.2011.07.007

Hipolito, L., Sanchez-Catalan, M. J., Zanolini, I., Polache, A., and Granero, L. (2008). Shell/core differences in mu- and delta-opioid receptor modulation of dopamine efflux in nucleus accumbens. Neuropharmacology 55, 183-189. doi: $\quad 10.1016 /$ j.neuropharm.2008. 05.012

Hipolito, L., Sanchez-Catalan, M J., Zornoza, T., Polache, A., and Granero, L. (2010). Locomotor stimulant effects of acute and repeated intrategmental injections of salsolinol in rats: role of mu-opioid receptors. Psychopharmacology (Berl) 209, 1-11. doi: 10.1007/s00213-0091751-9
Holtzman, S. G., and Schneider, F. H. (1974). Comparison of acetaldehyde and ethanol: depression of motor activity in mice. Life Sci. 14, 1243-1250. doi: 10.1016/00243205(74)90432-9

Hunt, W. A. (1996). Role of acetaldehyde in the actions of ethanol on the brain-a review. Alcohol 13, 147-151. doi: 10.1016/0741-8329(95)02026-8

Hurley, T. D., and Edenberg, H. J. (2012). Genes encoding enzymes involved in ethanol metabolism. Alcohol Res. 34, 339-344.

Huttunen, P., and Myers, R. D. (1987). Anatomical localization in hippocampus of tetrahydro-betacarboline-induced alcohol drinking in the rat. Alcohol 4, 181-187. doi: 10.1016/0741-8329(87)90041-3

Jacobsen, E. (1958). Et Præparat Fødes. Medicinisk Forum 58, 58-67.

Jamal, M., Ameno, K., Uekita, I., Kumihashi, M., Wang, W., and Ijiri, I. (2007). Catalase mediates acetaldehyde formation in the striatum of free-moving rats. Neurotoxicology 28, 1245-1248. doi: 10.1016/j.neuro.2007.05.002

Jarjour, S., Bai, L., and Gianoulakis, C. (2009). Effect of acute ethanol administration on the release of opioid peptides from the midbrain including the ventral tegmental area. Alcohol. Clin. Exp. Res. 33, 1033-1043. doi: 10.1111/j.15300277.2009.00924.x

Johnson, B. A., and Ait-Daoud, N. (2000). Neuropharmacological treatments for alcoholism: scientific basis and clinical findings. Psychopharmacology 149, 327-344. doi: $10.1007 / \mathrm{s} 002130000371$

Karahanian, E., Quintanilla, M. E., Tampier, L., Rivera-Meza, M., Bustamante, D., Gonzalez-Lira, V., et al. (2011). Ethanol as a prodrug: brain metabolism of ethanol mediates its reinforcing effects. Alcohol. Clin. Exp. Res. 35, 606-612. doi: 10.1111/j.1530-0277.2011.01439.x

Kiianmaa, K., and Virtanen, P. (1978). Ethanol and acetaldehyde levels in cerebrospinal fluid during ethanol oxidation in the rat. Neurosci. Lett. 10, 181-186. doi: 10.1016/03043940(78)90032-0

Koechling, U. M., and Amit, Z. (1994). Effects of 3-amino-1 2, 4-triazole on brain catalase in the mediation of ethanol consumption in mice. Alcohol 11, 235-239. doi: 10.1016/0741-8329(94)90036-1

Koelsch, F. (1914). Uber neuartige gewerbliche Errankungen in Kalkstickstoffbetrieben. Munch. Med. Wochschr 61, 1869-1970.

Kunin, D., Latendresse, M. W., Gaskin, S., Smith, B. R., and Amit, 
Z. (2000). Preexposure effects of nicotine and acetaldehyde on conditioned taste aversion induced by both drugs. Pharmaocol. Biochem. Behav. 66, 695-699. doi: 10.1016/S0091-3057(00)00284-7

Larsen, V. (1948). The effect of experimental animals of antabuse (tetraethylthiuramdisulphide) in combination with alcohol. Acta Pharmacol. 4, 321-332. doi: 10.1111/j.16000773.1948.tb03354.x

Ledesma, J. C., and Aragon, C. (2013). Acquisition and reconditioning of ethanol-induced conditioned place preference in mice is blocked by the $\mathrm{H}_{2} \mathrm{O}_{2}$ scavenger alpha lipoic acid. Psychopharmacology 226, 673-685. doi: 10.1007/s00213-012-2831-9

Ledesma, J. C., Font, L., and Aragon, C. (2012). The $\mathrm{H}_{2} \mathrm{O}_{2}$ scavenger ebselen decreases ethanol-induced locomotor stimulation in mice. Drug Alcohol Depend. 124, 42-49. doi: 10.1016/j.drugalcdep.2011.12.003

Lee, J., Ramchandani, V. A., Hamazaki, K., Engleman, E. A., McBride, W. J., Li, T. K., et al. (2010). A critical evaluation of influence of ethanol and diet on salsolinol enantiomers in humans and rats. Alcohol. Clin. Exp. Res. 34, 242-250. doi: 10.1111/j.1530-0277.2009.01087.x

Li, T. K. (2000). Pharmacogenetics of responses to alcohol and genes that influence alcohol drinking. J. Stud. Alcohol 61, 5-12.

Lovinger, D. M., and White, G. (1991). Ethanol potentiation of 5-hydroxytryptamine3 receptor-mediated ion current in neuroblastoma cells and isolated adult mammalian neurons. Mol. Pharmacol. 40, 263-270.

Lovinger, D. M., White, G., and Weight, F. F. (1989). Ethanol inhibits NMDA-activated ion current in hippocampal neurons. Science 243, 1721-1724. doi: 10.1126/science. 2467382

Lovinger, D. M., and Zhou, Q. (1998). Alcohol effects on the 5-HT3 ligand-gated ion channel. Toxicol. Lett. 100-101, 239-246. doi: 10.1016/S0378-4274(98)00191-X

Marti-Prats, L., Sanchez-Catalan, M. J., Hipolito, L., Orrico, A., Zornoza, T., Polache, A., et al. (2010). Systemic administration of D-penicillamine prevents the locomotor activation after intraVTA ethanol administration in rats. Neurosci. Lett. 483, 143-147. doi: 10.1016/j.neulet.2010.07.081

March, S. M., Abate, P., Spear, N. E., and Molina, J. C. (2013). The role of acetaldehyde in ethanol reinforcement assessed by Pavlovian conditioning in newborn rats. Psychopharmacology 226, 491-499. doi: 10.1007/s00213-012-2920-9

Maruyama, W., Nakahara, D., Dostert, P., Hashiguchi, H., Ohta, S., Hirobe, M., et al. (1993). Selective release of serotonin by endogenous alkaloids, 1-methyl-6, 7-dihydroxy-1 2, 3, 4-tetrahydroisoquinolines, (R)and (S)salsolinol, in the rat striatum; in vivo microdialysis study. Neurosci. Lett. 149, 115-118. doi: 10.1016/0304-3940(93)90749-B

Matsuzawa, S., Suzuki, T., and Misawa, M. (2000). Involvement of muopioid receptor in the salsolinolassociated place preference in rats exposed to conditioned fear stress. Alcohol. Clin. Exp. Res. 24, 366-372.

McBride, W. J., and Li, T. K. (1998). Animal models of alcoholism: neurobiology of high alcoholdrinking behavior in rodents. Crit. Rev. Neurobiol. 12, 339-369. doi: 10.1615/CritRevNeurobiol.v12. i4. 40

McCoy, J. G., Strawbridge, C., McMurtrey, K. D., Kane, V. B., and Ward, C. P. (2003). A re-evaluation of the role of tetrahydropapaveroline in ethanol consumption in rats. Brain Res. Bull. 60, 59-65. doi: 10.1016/S0361-9230(03)00018-2

Melchior, C. L., and Myers, R. D. (1977). Preference for alcohol evoked by tetrahydropapaveroline (THP) chronically infused in the cerebral ventricle of the rat. Pharmacol. Biochem. Behav. 7, 19-35. doi: 10.1016/0091-3057(77)90006-5

Melis, M., Enrico, P., Peana, A. T., and Diana, M. (2007). Acetaldehyde mediates alcohol activation of the mesolimbic dopamine system. Eur. J. Neurosci. 26, 2824-2833. doi: $\quad 10.1111 / j .1460-9568.2007$. 05887.x

Mereu, G., Fadda, F., and Gessa, G. L. (1984). Ethanol stimulates the firing rate of nigral dopaminergic neurons in unanesthetized rats. Brain Res. 292, 63-69. doi: 10.1016/00068993(84)90890-4

Mihic, S. J. (1999). Acute effects of ethanol on GABAA and glucine receptor function. Neurochem. Int. 35, 115-123. doi: 10.1016/S01970186(99)00053-4

Mihic, S. J., Ye, Q., Wick, M. J., Koltchine, V. V., Krasowski, M. D., Fin, S. E., et al. (1997). Sites of alcohol and volatile anaesthetic action on $\operatorname{GABA}(\mathrm{A})$ and glucine receptors. Nature 389, 385-389. doi: $10.1038 / 38738$

Myers, W. D., Gibson, S., Ng, K. T., and Singer, G. (1987). Sex differences in acetaldehyde on body temperature and open-field performance in the rat. Drug Alcohol Depend. 19, 1-6. doi: 10.1016/0376-8716(87)90081-0

Myers, R. D., and Melchior, C. L. (1977). Alcohol drinking: abnormal intake caused by tetrahydropapaveroline in brain. Science 196, 554-556. doi: 10.1126/science. 557839

Myers, W. D., Ng, K. T., and Singer, G. (1984a). Effects of naloxone and buprenorphine on intravenous acetaldehyde self-injection in rats. Physiol. Behav. 33, 449-455. doi: 10.1016/0031-9384(84)90168-9

Myers, W. D., Ng, K. T., Marzuki, S., Myers, R. D., and Singer, G. (1984b). Alteration of alcohol drinking in the rat by peripherally self-administered acetaldehyde. Alcohol 1, 229-236. doi: 10.1016/0741-8329(84)90103-4

Myers, R. D., and Oblinger, M. M. (1977). Alcohol drinking in the rat induced by acute intra-cerebral infusion of two tetrahydroisoquinolines and a beta-carboline. Drug Alcohol Depend. 2, 469-483. doi: 10.1016/0376-8716(77)90047-3

Myers, R. D., and Privette, T. H. (1989). A neuroanatomical substrate for alcohol drinking: identification of tetrahydropapaveroline (THP)-reactive sites in the rat brain. Brain Res. Bull. 22, 899-911. doi: 10.1016/0361-9230 (89)90035-X

Myers, R. D., and Robinson, D. E. (1999). Tetrahydropapaveroline injected in the ventral tegmental area shifts dopamine efflux differentially in the shell and core of nucleus accumbens in high-ethanol-preferring (HEP) rats. Alcohol 18, 83-90. doi: 10.1016/S0741-8329(99)00008-7

Myers, R. D., and Veale, W. L. (1969). Alterations in volitional alcohol intake produced in rats by chronic intraventricular infusions of acetaldehyde, paraldehyde or methanol. Arch. Int. Pharmacodyn Ther. 180, 100-113.

Nagasawa, H. T., Goon, D. J., and DeMaster, E. G. (1978). 2 5, 5 Trimethylthiazolidine-4-carboxylic acid, a D(-)-penicillaminedirected pseudometabolite of ethanol. Detoxication mechanism for acetaldehyde. J. Med Chem. 21, 1274-1279. doi 10.1021/jm00210a019

Nakahara, D., Maruyama, W. Hashiguti, H., and Naoi, M. (1994). Characterization of the in vivo action of (R)-salsolinol, an endogenous metabolite of alcohol, on serotonin and dopamine metabolism: a microdialysis study.
Brain Res. 644, 226-232. doi: 10.1016/0006-8993(94)91684-5

Narahashi, T., Aistrup, G. L., Marszalec, W., and Nagata, K. (1999). Neuronal nicotinic acetylcholine receptors: a new target site of ethanol. Neurochem. Int. 35, 131-141. doi: 10.1016/S0197-0186(99)00055-8

Nizhnikov, M. E., Molina, J. C., and Spear, N. E. (2007). Central reinforcing effects of ethanol are blocked by catalase inhibition. Alcohol 41, 525-534. doi: 10.1016/j.alcohol.2007.08.006

Oades, R. D., and Halliday, G. M. (1987). Ventral tegemental (A10) system: neurobiology. 1. Anatomy connectivity. Brain Res. 434, 117-165.

Ocaranza, P., Quintanilla, M. E., Tampier, L., Karahanian, E., Sapag, A., and Israel, Y. (2008). Gene therapy reduces ethanol intake in an animal model of alcohol dependence. Alcohol. Clin. Exp. Res. 32, 52-57. doi: 10.1111/j.1530-0277.2007.00553.x

Orrico, A., Hipolito, L., SanchezCatalan, M. J., Marti-Prats, L., Zornoza, T., Granero, L., et al. (2013). Efficacy of Dpenicillamine, a sequestering acetaldehyde agent, in the prevention of alcohol relapse drinking in rats. Psychopharmacology 228, 563-575. doi: 10.1007/s00213-0133065-1

Ortiz, A., Griffiths, P. J., and Littleton, J. M. (1974). A comparison of the effects of chronic administration of ethanol and acetaldehyde to mice: evidence for a role of acetaldehyde in ethanol dependence. J. Pharm. Pharmacol. 26, 249-260. doi: 10.1111/j.20427158.1974.tb09266.x

Pastor, R., and Aragon, C. (2008) Ethanol injected into the hypothalamic arcuate nucleus induced behavioral stimulation in rats: an effect prevented by catalase inhibition and naltrexone. Behav. Pharmacol. 19, 698-705. doi: 10.1097/FBP.0b01 3 e328315ecd7

Pautassi, R. M., Nizhnikov, M. E., Fabio, M. C., and Spear, N. E. (2011). An acetaldehydesequestering agent inhibits appetitive reinforcement and behavioral stimulation induced by ethanol in preweanling rats. Pharmacol. Biochem. Behav. 97, 462-469. doi: 10.1016/j.pbb.2010. 10.005

Peana, A. T., Assaretti, A. R. Muggironi, G., Enrico, P., and Diana, M. (2009). Reduction of ethanol-derived acetaldehyde induced motivational properties 
by L-cysteine. Alcohol. Clin. Exp. Res. 33, 43-48. doi: 10.1111/j.15300277.2008.00809.x

Peana, A. T., Enrico, P., Assaretti, A. R., Pulighe, E., Muggironi, G., Nieddu, M., et al. (2008). Key role of ethanol-derived acetaldehyde in the motivational properties induced by intragastric ethanol: a conditioned place preference study in the rat. Alcohol. Clin. Exp. Res. 32, 249-258. doi: 10.1111/j.15300277.2007.00574.x

Peana, A. T., Muggironi, G., and Diana, M. (2010). Acetaldehydereinforcing effects: a study on oral self-administration behavior. Front. Psychiatry 1:23. doi: 10.3389/fpsyt.2010.00023

Peana, A. T., Muggironi, G., Fois, G. R., Zinellu, M., Sirca, D., and Diana, M. (2012). Effect of L-systeine on acetaldehyde self-administration. Alcohol 46, 489-497. doi: 10.1016/j.alcohol.2011.10.004

Peana, A. T., Muggironi, G., Fois, G. R., Zinellu, M., Vinci, S., and Acquas, E. (2011). Effect of opioid receptor blockade on acetaldehyde self-administration and ERK phosphorylation in the rat nucleus accumbens. Alcohol 45, 773-783. doi: 10.1016/j.alcohol. 2011.06.003

Peng, G. S., and Yin, S. J. (2009). Effect of the allelic variants of Aldehyde dehydrogenase ALDH2 2 2 and alcohol dehydrogenase $\mathrm{ADH}_{1} \mathrm{~B}^{\star} 2$ on blood acetaldehyde concentrations. Hum. Genomics 3, 121-127. doi: 10.1186/1479-7364-3-2-121

Petersen, D. R., and Tabakoff, B. (1979). Characterization of brain acetaldehyde oxidizing systems in the mouse. Drug Alcohol Depend. 4, 137-144. doi: 10.1016/0376-8716(79)90054-1

Pikkarainen, P. H., Salaspuro, M. P., and Lieber, C. S. (1979). A method for the determination of "free" acetaldehyde in plasma. Alcohol. Clin. Exp. Res. 3, 259-261. doi: 10.1111/j.15300277.1979.tb05311.x

Privette, T. H., Hornsby, R. L., and Myers, R. D. (1988). Buspirone alters alcohol drinking induced in rats by tetrahydropapaveroline injected into brain monoaminergic pathways. Alcohol 5, 147-152. doi: 10.1016/0741-8329(88)90012-2

Privette, T. H., and Myers, R. D. (1989). Anatomical mapping of tetrahy -dropapaveroline-reactive sites in brain mediating suppression of alcohol drinking in the rat. Brain Res. Bull. 22, 1039-1048. doi: 10.1016/03619230(89)90017-8
Purvis, P. L., Hirst, M., and Baskerville, J. C. (1980). Voluntary ethanol consumption in the rat following peripheral administrations of 3-carboxy-salsolinol. Subst. Alcohol Actions. Misuse 1, 439-445.

Quertemont, E., and DeWitte, P. (2001). Conditioned stimulus preference after acetaldehyde but not ethanol injections. Pharmacol. Biochem. Behav. 68, 449-454. doi: 10.1016/S0091-3057(00)00486-X

Quertemont, E., Grant, K. A., Correa, M., Arizzi, M. N., Salamone, J. D., Tambour, S., et al. (2005). The role of acetaldehyde in the central effects of ethanol. Alcohol. Clin. Exp. Res. 29, 221-234. doi: 10.1097/01.ALC.0000156185. 39073.D2

Quertemont, E., Tambour, S., Bernaerts, P., Zimatkin, S. M., and Tirelli, E. (2004). Behavioral characterization of acetaldehyde in $\mathrm{C} 57 \mathrm{BL} / 6 \mathrm{~J}$ mice: locomotor, hypnotic, anxiolytic and amnesic effects. Psychopharmacology (Berl.) 177, 84-92. doi: 10.1007/s00213004-1911-x

Quintanilla, M. E., Callejas, O., and Tampier, L. (2002). Aversion to acetaldehyde: differences in lowalcohol drinking (UChA) and high-alcohol drinking (UChB) rats. Alcohol 26, 69-74. doi: 10.1016/S0741-8329(01)00197-5

Quintanilla, M. E., and Tampier, L. (2003). Acetaldehyde-reinforcing effects: differences in lowalcohol-drinking (UChA) and high-alcohol-drinking (UChB) rats. Alcohol 31, 63-69. doi: 10.1016/j.alcohol.2003.07.001

Quintanilla, M. E., Tampier, L., Karahanian, E., Rivera-Meza, M., Herrera-Marschitz, M., and Israel, Y. (2012). Reward and Relapse: complete gene-induced dissociation in an animal model of alcohol dependence. Alcohol. Clin. Exp. Res. 36, 517-522. doi: 10.1111/j.1530-0277.2011.01606.x

Raskin, N. H. (1975). Editorial: alcoholism or acetaldehydism. $N$. Engl. J. Med. 292, 422-423. doi: 10.1056/NEJM197502202920811

Rehm, J., Mathers, C., Popova, S., Thavorncharoensap, M., Teerawattananon, Y., and Patra, J. (2009). Global burden of disease and injury and economic cost attributable to alcohol use and alcohol-use disorders. Lancet 373, 2223-2233. doi: 10.1016/S0140-6736(09)60746-7

Reynolds, W. A., and Lowe, F. H. (1965). Mushrooms and a toxic reaction to alcohol: report of Four Cases. N. Engl.
J. Med. 272, 630-631. doi 10.1056/NEJM196503252721209

Rhoads, D. E., Contreras, C., and Fathalla, S. (2012). Brain levels of catalase remain constant through strain, development, and chronic alcohol challenges. Enzyme Res. 2012, 1-6. doi: 10.1155/2012/ 572939

Rivera-Meza, M., Quintanilla, M. E., and Tampier, L. (2012). Reduction of ethanol consumption in alcoholpreferring rats by dual expression gene transfer. Alcohol Alcohol. 47, 102-108. doi: 10.1093/alcalc/agr161

Rivera-Meza, M., Quintanilla, M. E., Tampier, L., Mura, C. V., Sapag, A., and Israel, Y. (2010). Mechanism of protection against alcoholism by an alcohol dehydrogenase polymorphism: development of an animal model. FASEB J. 24, 266-274. doi: 10.1096/fj.09-132563

Rodd, Z. A., Bell, R. L., Zhang, Y., Goldstein, A., Zaffaroni, A., McBride, W. J., et al. (2003). Salsolinol produces reinforcing effects in the nucleus accumbens shell of alcohol-preferring $(\mathrm{P})$ rats Alcohol. Clin. Exp. Res. 27, 440-449. doi: 10.1097/01.ALC.0000056612. 89957.B4

Rodd, Z. A., Bell, R. L., Zhang, Y., Murphy, J. M., Goldstein, A., Zaffaroni, A., et al. (2005) Regional heterogeneity for the intracranial self-administration of ethanol and acetaldehyde within the ventral tegmental area of alcohol-preferring $(\mathrm{P})$ rats: involvement of dopamine and serotonin. Neuropsychopharmacology $\quad 30$ 330-338. doi: 10.1038/sj.npp. 1300561

Rodd, Z. A., Oster, S. M., Ding, Z. M., Toalston, J. E., Deehan, G., Bell, R. L., et al. (2008). The reinforcing properties of salsolinol in the ventral tegmental area: evidence for regional heterogeneity and the involvement of serotonin and dopamine. Alcohol. Clin. Exp. Res. 32, 230-239. doi: 10.1111/j.1530-0277.2007.00572.x

Rodd-Henricks, Z. A., Melendez, R. I., Zaffaroni, A., Goldstein, A., McBride, W. J., and Li, T. K. (2002). The reinforcing effects of acetaldehyde in the posterior ventral tegmental area of alcohol-preferring rats. Pharmacol. Biochem. Behav. 72, 55-64. doi: 10.1016/S0091-3057(01)00733-X

Rojkovicova, T., Mechref, Y., Starkey, J. A., Wu, G., Bell, R. L., McBride, W. J., et al. (2008). Quantitative chiral analysis of salsolinol in different brain regions of rats genetically predisposed to alcoholism.
J. Chromatogr. B Anal. Technol. Biomed. Life Sci. 863, 206-214. doi: 10.1016/j.jchromb.2008.01.016

Rotzinger, S., Smith, B. R., and Amit, Z. (1994). Catalase inhibition attenuates the acquisition of ethanol and saccharin-quinine consumption in laboratory rats. Behav. Pharmacol. 5, 203-209. doi: 10.1097/00008877199404000-00012

Sanchez-Catalan, M. J., Hipolito, L., Zornoza, T., Polache, A., and Granero, L. (2009). Motor stimulant effects of ethanol and acetaldehyde injected into the posterior ventral tegmental area of rats: role of opioid receptors. Psychopharmacology 204, 641-653. doi: 10.1007/s00213-009-1495-6

Sanchis-Segura, C., Correa, M., Miquel, M., and Aragon, C. (2005). Catalase inhibition in the arcuate nucleus blocks ethanol effects on the locomotor activity of rats. Neurosci. Lett. 376, 66-70. doi: 10.1016/j.neulet.2004.11.025

Sippel, H. W. (1974). The acetaldehyde content in rat brain during ethanol metabolism. J. Neurochem. 23, 451-452. doi: 10.1111/j.14714159.1974.tb04380.x

Smith, B. R., Amit, Z., and Splawinsky, J. (1984). Conditioned place preference induced by intraventricular infusions of acetaldehyde. Alcohol 1, 193-195. doi: 10.1016/0741-8329 (84)90097-1

Smith, B. R., Aragon, C. M., and Amit, Z. (1997). Catalase and the production of brain acetaldehyde: a possible mediator of the psychopharmacological effects of ethanol. Addict. Biol. 2, 277-289. doi: 10.1080/13556219772570

Spanagel, R. (2009). Alcoholism: a systems approach from molecular physiology to addictive behavior. Physiol. Rev. 89, 649-705. doi: 10.1152/physrev.00013.2008

Spanagel, R., Herz, A., and Shippenberg, T. S. (1992). Opposing tonically active endogenous opioid systems modulate the mesolimbic dopaminergic pathway. Proc. Natl. Acad. Sci. U.S.A. 89, 2046-2050. doi: 10.1073/pnas.89.6.2046

Spina, L., Longoni, R., Vinci, S., Ibba, F., Peana, A. T., Muggironi, G. et al. (2010). Role of dopamine D1 receptors and extracellular signal regulated kinase in the motivational properties of acetaldehyde as assessed by place preference conditioning. Alcohol. Clin. Exp. Res. 34, 607-616. doi: 10.1111/j.15300277.2009.01129.x

Stotz, E. (1943). A colorimetric determination of acetaldehyde in blood. J. Biol. Chem. 148, 585-591. 
Tabakoff, B., Anderson, R. A., and Ritzmann, R. F. (1976). Brain acetaldehyde after ethanol administration. Biochem. Pharmacol. 25, 1305-1309. doi: 10.1016/0006-2952 (76)90094-0

Takayama, S.,and Uyeno, E. T. (1985). Intravenous self-administration of ethanol and acetaldehyde by rats. Yakubutsu. Seishin. Kodo 5, 329-334.

Tambour, S., Didone, V., Tirelli, E.,and Quertemont, E. (2006). Locomotor effects of ethanol and acetaldehyde after peripheral and intraventricular injections in Swiss and C57BL/6J mice. Behav. Brain Res. 172, 145-154. doi: 10.1016/j.bbr.2006.05.010

Tampier, L., and Quintanilla, M. E. (2002). Effect of acetaldehyde on acute tolerance and ethanol consumption in drinker and nondrinker rats. J. Stud. Alcohol 63, 257-262.

Tampier, L., Quintanilla, M. E., Karahanian, E., Rivera-Meza, M., Herrera-Marschitz, M.,and Israel, Y. (2013). The alcohol deprivation effect: marked inhibition by anticatalase gene administration into the ventral tegmental area in rats. Alcohol. Clin. Exp. Res. 37, 1278-1285. doi: 10.1111/acer.12101

Tampier, L., Quintanilla, M. E., Mardones, J. (1995). Effects of aminotriazole on ethanol, water, and food intake and on brain catalase in UChA and UChB rats. Alcohol 12, 341-344. doi: 10.1016/0741-8329(95)00014-I

Truitt, E. B. Jr., and Walsh, M. J. (1971).

"The role of acetaldehyde in the actions of ethanol," in The Biology of Alcoholism, eds B. Kissin and $\mathrm{H}$.
Begleiter (New York, NY: Plenum Press), 161-195. doi: 10.1007/9781-4615-6525-3_5

Tuomisto, L., Airaksinen, M. M., Peura, P.,and Eriksson, C. J. (1982). Alcohol drinking in the rat: increases following intracerebroventricular treatment with tetrahydro-beta-carbolines. Pharmacol. Biochem. Behav. 17, 831-836. doi: 10.1016/0091-3057 (82)90367-7

Tuomisto, L., and Tuomisto, J. (1973). Inhibition of monoamine uptake in synaptosomes by tetrahydroharmane and tetrahydroisoquinoline compounds. Naunyn Schmiedebergs Arch. Pharmacol. 279, 371-380. doi: 10.1007/BF00500802

Valenta, J. P., Job, M. O., Mangieri, R. A., Schier, C. J., Howard, E. C., and Gonzales, R. A. (2013). $\mu$ Opioid receptors in the stimulation of mesolimbic dopamine activity by ethanol and morphine in Long-Evans rats: a delayed effect of ethanol. Psychopharmacology 228, 389-400. doi: 10.1007/s00213-0133041-9

Vasiliou, V., Ziegler, T. L., Bludeau, P., Petersen, D. R., Gonzalez, F. J., and Deitrich, R. A. (2006). CYP2E1 and catalase influence ethanol sensitivity in the central nervous system. Pharmacogenet. Genomics 16, 51-58. doi: 10.1097/01.fpc. 0000182777.95555 .56

Vengeliene, V., Bilbao, A., Molander, A., and Spanagel, R. (2008). Neuropharmacology of alcohol addiction. Br. J. Pharmacol. 154, 299-315. doi: 10.1038/bjp.2008.30

Walsh, M. J., Davis, V. E., and Yamanaka, Y. (1970).
Tetrahydropapaveroline: an alkaloid metabolite of dopamine in vitro. J. Pharmacol. Exp. Ther. 174, 388-400.

Ward, R. J., Colantuoni, C., Dahchour, A., Quertemont, E., and De Witte, P. (1997). Acetaldehyde-induced changes in monoamine and amino acid extracellular microdialysate content of the nucleus accumbens. Neuropharmacology 36, 225-232. doi: 10.1016/S0028-3908 (97)00007-5

Williams, E. E. (1937). Effects of alcohol on workers with carbon disulfide. J. Am. Med. Assoc. 109, 1472-1473.

Xie, G., Hipolito, L., Zuo, W., Polache, A., Granero, L., Krnjevic, K., and Ye, J. H. (2012a). Salsolinol stimulates dopamine neurons in slices of posterior ventral tegmental area indirectly by activating $\mu$-opioid receptors. J. Pharmacol. Exp. Ther. 341 43-50. doi: 10.1124/jpet.111.186833

Xie, G., and Ye, J. H. (2012b). Salsolinol facilitates glutamatergic transmission to dopamine neurons in the posterior ventral tegmental area of rats. PLoS ONE 7:e36716. doi: 10.1371/journal.pone.0036716

Ye, J. H., Tao, L., Ren, J., Schaefer, R., Krnjevic, K., Liu, P. L. et al. (2001). Ethanol potentiation of glycineinduced responses in dissociated neurons of rat ventral tegmental area. J. Pharmacol. Exp. Ther. 296, 77-83.

Zakhari, S. (2006). Overview: how is alcohol metabolized by the body. Alcohol Res. Health 29, 245-254.

Zimatkin, S. M. (1991). Histochemical study of aldehyde dehydrogenase in the rat CNS. J. Neurochem.
56, 1-11. doi: 10.1111/j.14714159.1991.tb02555.x

Zimatkin, S. M., Liopo, A. V.,and Deitrich, R. A. (1998). Distribution and kinetics of ethanol metabolism in rat brain. Alcohol. Clin. Exp. Res. 22, 1623-1627. doi: 10.1111/j.15300277.1998.tb03958.x

Conflict of Interest Statement: The authors declare that the research was conducted in the absence of any commercial or financial relationships that could be construed as a potential conflict of interest.

Received: 06 May 2013; paper pending published: 01 June 2013; accepted: 27 July 2013; published online: 23 August 2013.

Citation: Deehan GA Jr, Hauser SR, Wilden JA, Truitt WA and Rodd ZA (2013) Elucidating the biological basis for the reinforcing actions of alcohol in the mesolimbic dopamine system: the role of active metabolites of alcohol. Front. Behav. Neurosci. 7:104. doi: 10.3389/ fnbeh.2013.00104

This article was submitted to the journal Frontiers in Behavioral Neuroscience.

Copyright (c) 2013 Deehan, Hauser, Wilden, Truitt and Rodd. This is an open-access article distributed under the terms of the Creative Commons Attribution License (CC BY). The use, distribution or reproduction in other forums is permitted, provided the original author(s) or licensor are credited and that the original publication in this journal is cited, in accordance with accepted academic practice. No use, distribution or reproduction is permitted which does not comply with these terms. 